\title{
Informella lärmiljöers effekter på elevers lärande och intresse för naturvetenskap: En översikt
}

\author{
Per Anderhag \\ Stockholms universitet
}

Informella lärmiljöer såsom museer, djurparker och science centers kännetecknas av att de är öppna för allmänheten och att de inte behöver ha en formell koppling till skolväsendet. Denna artikel syftar till att ge en översiktlig beskrivning av forskning om informella lärmiljöers effekter på elevers lärande och intresse för naturvetenskap. Forskningen visar att informella lärmiljöer kan påverka elevers lärande och intresse positivt. Samtidigt är kunskapen begränsad om hur detta går till och vilken betydelse besök har för ett mer beständigt intresse. Studierna lyfter särskilt (1) det sociala sammanhang som miljöerna erbjuder, (2) möjligheten till alternativa ingångar till naturvetenskap, samt (3) kopplingen till den reguljära skolverksamheten som viktiga aspekter för informella lärmiljöers möjlighet att påverka elevernas lärande och intresse. Utifrån detta diskuterar artikeln möjliga sätt som informella lärmiljöer kan kopplas till skolans formella undervisning i naturvetenskap.

\section{Inledning}

Denna text syftar till att ge en översiktlig beskrivning av informella lärmiljöers effekter på elevers intresse och lärande i naturvetenskap. Översikten är inte heltäckande men bör ändå ge en god beskrivning av området. Informella lärmiljöer kan avse allt från publika akvarier, botaniska trädgårdar, science centers och tillfälliga museiutställningar till mer formaliserade och permanenta samarbeten mellan universitet och det obligatoriska skolväsendet. Även om det inte finns någon konsensusdefinition, är informella lärmiljöer en vedertagen term inom det naturvetenskapsdidaktiska forskningsfältet. Science centers är ofta det man förknippar med informella naturvetenskapliga lärmiljöer och kännetecknande för dessa verksamheter är att man vanligtvis har som mål att stödja elevers/allmänhetens förståelse och intresse för naturvetenskap (se t.ex. översikt av Falk \& Dierking [1]). Ofta sker detta genom att man erbjuder alternativa, ofta lustfyllda och praktiska, sätt att närma sig naturvetenskap. Upplevelser och känslor anses således vara viktiga för science centers möjlighet att stimulera elevers intresse och lärande i naturvetenskap, något som förstås även kan sägas gälla för naturvetenskaplig undervisning i stort [2,3]. Ibland finns ett nära samarbete med skolor kring till exempel lärarfortbildningar och elevmaterial. Inom begreppet Science centers kan således en heterogen grupp verksamheter inordnas (se $[4,5]$ för en historisk bakgrund till framväxandet av science centers).

Ytterligare ett begrepp som förekommer är Science Resource Centres/ naturvetenskapliga resurscentra. I likhet med vad som har diskuterats ovan finns det heller ingen allmänt vedertagen definition om vad som utmärker dessa. Ofta är resurscentra kopplade till universitet och högskolor och ofta riktar de sig primärt till lärare på olika nivåer i utbildningssystemet. Ytterligare begrepp som används i litteraturen är extramurala lärmiljöer, vilket avser lärande som sker utanför klassrummet [6], och field trips som i princip kännetecknas av att eleverna tas ur skolan och besöker ett museum, resurscentrum, zoo, gör en fältstudie, etc. På grund av det som beskrivits ovan kommer därför informella lärmiljöer användas som en övergripande term för alla dessa olika typer av verksamheter. Översikten bygger på rapporter från internationella intresse-organisationer, bokkapitel och artiklar publicerade i peer-reviewade tidskrifter. 


\section{Motiv och metoder för att studera informella lärmiljöer}

\section{Intresse viktigt för lärande}

I en översiktsrapport presenterar Bell med flera [7] ett antal områden som de menar vara kännetecknande för hur forskningsfältet har diskuterat och studerat informella lärmiljöer. I princip handlar det om vilken typ av kunskap och kompetenser dessa miljöer kan stödja. Mycket kortfattat fokuserar områdena, som i varierande grad har blivit utforskade, på aspekter som kan sägas känneteckna en gedigen förståelse för naturvetenskap som innehåll och praktik. Lite förenklat kan man säga att de argument som förs fram är att samhället behöver fler naturvetare och att naturvetenskaplig kunskap är en nödvändighet för att kunna göra kompetenta val i vardagen (media, hälsa, kost, energi, miljö). Det gäller både en själv men också ur ett demokratiperspektiv (se t.ex. [8]). Argumenten är i princip identiska med de som brukar lyftas i andra NV-didaktiska sammanhang.

Informella lärmiljöer kan alltså vara ett medel för ovanstående mål och enligt Bell med kollegor [7] har de också potential att påverka besökarens/elevens möjlighet att utveckla: (1) ett intresse för naturvetenskap, (2) sin förståelse för naturvetenskapliga fakta, (3) ett vetenskapligt sätt att resonera och förhålla sig till omvärlden (4) sin naturvetenskapliga allmänbildning, (5) en handlingskompetens, att kunna delta i naturvetenskapliga praktiker och (6) en naturvetenskaplig identitet. Intresse för naturvetenskap anses vara avgörande för deras lärande. Lite tillspetsat kan man säga att intresse ses som en drivkraft för att realisera de övriga punkterna [3,4].

\section{Metodologiska ansatser}

Den vanligaste formen för att studera hur elever och besökare påverkas av informella lärmiljöer har varit genom för- och eftertester, enkäter och intervjuer [9]. Dessa typer av insamlingsmetoder dominerar attitydforskningen generellt, oavsett vilket område, ämne, utbildningsinsats eller forskningsfråga man studerat [10]. Flera författare har dock ifrågasatt alltför enkla ansatser då dessa tenderar att reducera lärande till något som kan beskrivas genom enkla orsak-verkan samband. DeWitt och Hohenstein [11] menar också att för- och eftertester kan vara kontraproduktiva då sociala och känslomässiga dimensioner av besöket, vilket anses vara en styrka med informella lärmiljöer, tenderar att påverkas negativt av kunskapskontroller. Falk och Dierking [1] lyfter även det problematiska i att mäta effekter kopplade till formella kunskapsmål, vilket är vanligt i forskningen. De pekar på att informella lärmiljöer ofta fokuserar andra aspekter på naturvetenskap, såsom att ge alternativ till skolans naturvetenskap och en annorlunda social kontext.

På grund av svårigheten att mäta lärande och intresse i form av effektsamband har Falk med kollegor [9] föreslagit att det kan vara mer givande att fokusera på korrelation snarare än kausalitet gällande hur informella lärmiljöer kan påverka elevers lärande och intresse för naturvetenskap. Denna förändring i forskningsintresse torde delvis kunna förklaras av den successiva förskjutning i de teoretiska ramverk forskningsfältet har använt sig av. I likhet med övrig utbildningsvetenskaplig forskning har fokus förflyttats från behavioristiska försöksuppställningar till mer kognitivt-psykologiska och socialkonstruktivistiska ansatser för att idag vara mer sociokulturellt orienterat [12]. Det senare perspektivet kännetecknas bland annat av att det erkänner det sociala sammanhangets betydelse för lärande och intresse. I viss mån är detta också applicerbart på hur olika science centra och museer historiskt har valt att presentera naturvetenskap för sina besökare. Pedretti [13] beskriver detta i termer av paradigmskiften och i korthet kan processen sammanfattas som att man gått från att se på besökaren som en passiv mottagare till att idag förstå besökaren som en aktiv deltagare med en bakgrund (genus, social klass, etnicitet etc.) vilket antas ha betydelse för hur de kan förstå och interagera med det som förevisas [13]. 


\section{Lärares syften med att besöka informella lärmiljöer}

Ett annat område där det finns en del forskning handlar om vilka motiv lärare anger till varför de väljer att besöka en informell lärmiljö. I en studie av Kiesiel [14] presenteras åtta olika motiv som lärare anger till varför de väljer att ta sina elever till museum och science centers: (1) för att tydliggöra aspekter i kursplanen, (2) för att stimulera elevers lärande generellt, (3) för att stimulera till livslångt lärande, (4) för att öka elevernas motivation och intresse, (5) för att låta eleverna få nya erfarenheter, (6) för att erbjuda ett avbrott till de vanliga rutinerna, (7) för att det är kul och (8) för att möta skolans förväntningar på att sådana besök ska ske.

Lärarna i Kiesels [14] studie gav mycket olika beskrivningar om vad kopplingen till kursplanen kunde innebära. Även om de generellt ansåg detta vara ett mycket viktigt motiv, avhandlades ändå kursplanen tämligen symboliskt av lärarna. Andra studier har visat att sociala aspekter, liknande punkt 5-7 ovan, ofta är en huvudanledning till besöket $[15,16]$. I vissa fall handlar det då om att ge eleverna möjligheter att socialisera med varandra under andra, mer fria och informella, förhållanden än vad som vanligtvis sker i en skolmiljö. Lärarna menar att detta är betydelsefullt för elevernas lärande men också att det är berikande och därmed viktigt för deras personliga utveckling. Studier har även visat att sådana tillfällen kan vara betydelsefulla för elevens mer allmänna välbefinnande [17] men också för deras attityder och förståelse för naturvetenskap [18]. Kritik har dock riktats mot en alltför stor tilltro till att roliga och intressanta besök automatiskt leder till en kunskapsutveckling [16]. Det finns även studier som har visat att samtidigt som eleverna beskriver aktiviteter som roliga och intressanta har det liten effekt på deras lärande eller mer beständiga intresse [3,8,13,19,20].

För att undvika att besöket blir en isolerad händelse med liten relevans för elevernas utveckling är det viktigt att läraren förbereder eleverna och att det sker någon form av återkoppling efteråt. Läraren har således en mycket viktig roll i att koppla samman det eleverna möter under besöket med kurs- och ämnesplaner. [20-24]. Studier som har undersökt dessa aspekter har dock visat att förberedelse- och uppföljningsarbete är tämligen sparsamt förekommande [21,23,25,26] och att det varierar mellan skolor, årskurser och sammanhang [27], trots att lärare anser att det är viktigt [24].

\section{Effekter av besök i informella lärmiljöer}

Nedan presenteras forskning som studerat effekter av informella lärmiljöer. Jag har valt att presentera effekter på lärande och attityder, som till exempel intresse, tillsammans men skiljer på studier som undersökt kortsiktiga och mer beständiga effekter. Översikten är knappast heltäckande men jag har försökt ge en representativ bild över vad forskningen visar om informella lärmiljöers effekter på lärande och intresse.

Det stora flertalet studier berör olika varianter på följande teman: attityders betydelse för lärande, vikande intresse för naturvetenskap, ett alternativ till traditionella skolmiljöer där det finns annorlunda, och kanske också större, möjligheter att påverka elevers intresse [1,7]. Flertalet studier bygger på enkäter och för- och eftertest, men det finns också en diskussion inom fältet som rör metodologiska och teoretiska ansatser där flera författare problematiserar idén om att hitta enkla kausalitetssamband när lärande studeras [7,19].

\section{Besökets effekter på lärande och intresse på kort sikt}

Tidigare forskning har visat att elever ofta kommer ihåg besök i informella lärmiljöer och att besöken dessutom har potential att påverka elevernas lärande och attityder [7,28-32]. Studier har också visat att sådana effekter, speciellt gällande elevernas lärande, tenderar att påverkas positivt av stödjande uppföljningsaktiviteter i klassrummet [33-35]. I till exempel Bozdogans och Yalcins [22] studie, som visade på signifikanta effekter på elevers intresse och förståelse, lyfts betydelsen av att det finns en koppling mellan besöket och kursplaner. Författarna menar också att 
uppföljningsaktiviteterna bör ske inom en viss tid efter besöket. I studien, som genomfördes på ett science center i Turkiet, fick 31 högstadieelever svara på två olika för-tester som mätte deras kunskap i och intresse för naturvetenskap. Efter besöket (direkt efter och fem veckor senare) uppvisade eleverna ett ökat intresse och kunskap i de områden som de hade arbetat med på science centret.

Det tycks således vara tämligen vedertaget och oproblematiskt att informella lärmiljöer kan påverka elevers lärande och intresse i naturvetenskap (se t.ex. [5,9,18,36]). Det kan vara värt att poängtera att det är lite som skiljer ovanstående studier från de som har genomförts i konventionella klassrum där man velat utvärdera en alternativ undervisningsmetod eller intressestimulerande moment (se t.ex. [8,10]), det vill säga: olika aspekter rörande stoff, kontext, metoder och så vidare kan påverka elevers lärande och intresse, vilket knappast är förvånande. Dewitt och Hohenstein [11] visade dock i sin studie att det kan vara kvalitativa skillnader i hur elever pratar med varandra i NV-klassrummet och när de besöker en informell lärmiljö. Under besöket på två olika museer (the Science Museum, London och the New York Hall of Science) var eleverna mer känslomässigt engagerade och dessutom mer fokuserade på det naturvetenskapliga stoffet jämfört med vad som observerades i klassrummen.

I sammanhang där man studerat hur besökare på museum pratar med varandra har man visat på egenskaper i dessa samtal som kan vara av betydelse för lärande, till exempel är de tydligt ämnesfokuserade och besökarna pratar om vad de ser och hur detta relaterar till deras tidigare erfarenheter [37,38]. I en studie av Sample McMeeking med kollegor [32] uppskattade de deltagande mellanstadieelever besökets sociala aspekter högt. Detta stöds av Ayar [39] som visade att begränsningar i elevernas möjlighet att röra sig fritt och socialisera (på grund av tid och utrymme) under ett besök hade negativ påverkan på elevernas intresse. Dessutom visade Godec [40] i en studie att informella miljöer kan vara viktiga för flickors möjlighet att närma sig naturvetenskap, detta då sådana miljöer öppnar upp för alternativa synsätt på hur en naturvetenskapsperson ska vara. Sammantaget antyder detta att informella lärmiljöer kan påverka hur elever samtalar och interagerar kring ett naturvetenskapligt innehåll.

Falk och Dierking [1] har sammanfattat ett antal faktorer som de menar påverkar lärandet i informella lärmiljöer, nämligen:

- Möjligheten till aktivt och meningsfullt deltagande - oftast praktiska och/eller upplevelserika moment

- Elevens förförståelse - stoff, sammanhang, syften,

- För- och efterarbete - t.ex. material och uppgifter, och

- Den specifika sociala kontexten - nytt och spännande, annorlunda, etc.

Dohn Bonderup [41] visade också i en studie på elever som besökte ett zoo, att intresse stimuleras när flera faktorer samverkar. Författaren lyfter framförallt: aktiv delaktighet, nyhetsfaktor, känsla av förvåning och graden av kunskapsinhämtning som viktiga faktorer (vilket relaterar till första och fjärde punkten ovan) för elevernas intresse.

Elevernas möjlighet att delta på ett meningsfullt sätt lyfts även i Orion och Hofsteins [42] studie av 296 elever när de deltog på en geologiexkursion. De kunde till exempel visa att strukturer som hjälper eleverna att interagera med det de ska undersöka är avgörande för att insatsen ska ha någon effekt på deras lärande. En annan viktig faktor är den möjlighet eleverna har att relatera till det som besöket fokuserar. Därmed är deras förförståelse av betydelse, dels i termer av förståelse för stoffet men också deras förståelse för besöket som sådant (plats, socialt sammanhang etc.). Anderson och Nashon [43] beskriver detta i termer av metakognition och visar i en studie hur elevernas förmåga att kunna förhålla sig till sin kunskapsinhämtning har betydelse för vilket lärande som sker under ett besök på ett tivoli. 
I Stavrova och Urhahnes [44] studie undersöktes vilka effekter två varianter av ett guidat museiprogram hade på elevernas lärande och attityder till naturvetenskap. Studien visade att båda programmen hade positiv effekt på elevernas förståelse för naturvetenskap. Den version som i högre utsträckning stimulerade ett aktivt deltagande, gruppinteraktion och innehöll en högre grad av variation hade dock en större påverkan på elevernas attityder. De elever som deltog i den modifierade versionen visade större intresse och motivation. De uppgav också att de kände sig mer kompetenta och var i mindre utsträckning uttråkade efter besöket. Detta stöds även av Bastens och kollegors [45] studie som visade att insatser som stimulerade elevernas självständighet, snarare än att kontrollera att de gjorde rätt, hade en positiv effekt på elevernas attityder och lärande.

\section{Effekter på lärande och intresse en längre tid efter besöket}

Det finns relativt få studier som har undersökt informella lärmiljöers mer långsiktiga effekter på elevers intresse och lärande i naturvetenskap [9]. På grund av svårigheten att isolera enskilda faktorers betydelse för lärande är detta knappast förvånande och samma sak gäller för intresse och lärande i naturvetenskap generellt. Intresse och förståelse för naturvetenskap utvecklas över tid och erfarenheter från en rad olika möten och händelser har betydelse för denna process.

De studier som finns antyder dock att informella lärmiljöer kan ha en beständig effekt på elevers intresse och lärande. I vissa av dessa studier har man undersökt om det finns någon relation mellan universitetsstudieval och besök på science centers [46,47]. I till exempel Salmis [48] studie svarade $79,8 \%$ av de tillfrågade universitetsstudenterna att de hade besökt ett specifikt science center (Heureka, Helsingfors) någon gång under sin skoltid. Studien visade att studenter på ingenjörs- och naturvetenskapsutbildningar i högre utsträckning, jämfört med studenter på humanistiska utbildningar, angav att de hade besökt det aktuella science centret. Enligt Salmi [48] visar skillnaderna i studieval att besöket har haft positiv effekt på deras intresse. Ett liknande resonemang förs i Coventrys [49] studie där $80 \%$ av de som studerade på NV-relaterade universitetsutbildningar hade åtminstone gjort ett besök på ett specifikt science center i Perth, Australien. Motsvarande siffra för studenter på humanistiska utbildningar var $64 \%$. Shaby och Vedder-Weiss [50] nyanserar ovanstående bild i en longitudinell studie (3 år), där de inte kunde observera några förändringar gällande besök i informella lärandemiljöer och hur eleverna såg på sig själva i relation till naturvetenskap.

Falk och Dierking [1] intervjuade vuxna och barn (9-10 och 13-14 år) om tidigare besök på science centers. Studien visade att även om flera år hade passerat kunde respondenterna återge besöket tämligen ingående, till exempel kunde de prata om saker som rörde innehåll, de kunde återge detaljer om interiör och utställningar, vem de hade varit där med och hur besöket hade påverkat dem känslomässigt. Av de som intervjuades angav 80\% att de hade tänkt på besöket efteråt. Att elever ofta kan ge detaljrika beskrivningar av sina upplevelser från ett besök på ett science center stöds även av Stevensons [51], Spocks [52] och Beiers och McRobbies [53] studier.

Flera av studierna lyfter det sociala sammanhanget som betydelsefullt för lärandet som sker under besöket och i en studie av Andersson [54] framhålls det som en helt avgörande faktor för vad individen kommer ihåg av ett besök. Andersson visade att de minnen respondenterna i studien spontant återgav 15-17 år efter att ha besökt en världsutställning framförallt handlade om det sociala sammanhanget. De kunde tämligen ingående beskriva vem de hade varit där med, vad de hade pratat om och hur de tillsammans hade upplevt olika aspekter av utställningen. I mindre utsträckning mindes de utställningens innehåll. Vidare visade studien att personernas dåvarande socio-kulturella identitet (vem man var då) var av betydelse för vad de såg som intressant och viktigt. Andersson menar därför att det är viktigt att skapa sociala länkar mellan utställning och individ, det vill säga man bör möjliggöra för besökaren att identifiera sig med det som förevisas.

Även om inte lärandeprogression varit primärfokus för alla studier ovan, visar samtliga att informella lärmiljöer kan ha en positiv effekt på elevers förståelse för naturvetenskap. I en studie visade Falk med kollegor [55] dessutom att 65\% av de intervjuade zoo- och akvariebesökarna kunde 
7 till 11 månader efter besöket berätta om vad de hade lärt sig. I en senare studie, som baseras på telefonenkäter med en slumpvis vald population, visade Falk och Needham [56] att 50\% av de tillfrågade ansåg att besök på ett science center hade haft bestående effekt på deras förståelse för och attityder till naturvetenskap och teknik. Forskarna [56] menar att resultatet är intressant då tidigare studier ofta har valt att intervjua eller ge enkäter till besökare på ett specifikt science centra, vilket innebär att man studerat individer som till en viss grad redan är intresserade (eftersom de är där). Studien har dock mött tämligen hård kritik, dels utifrån dess teoretiska antaganden och dels utifrån metoddesign och de statistiska analyser som resultatet bygger på [57].

I en rapport om långtgående effekter på elevers lärande och intresse ifrågasätter författarna ansatsen att hitta tydliga kausalitetsamband mellan besök på ett visst science center och karriärväg [9]. Till exempel kan man ifrågasätta huruvida frekvensen av besök som rapporteras på en universitetsstudieinriktning visar på ett faktiskt orsaksförhållande mellan besök och studieval. Falk med kollegor [9] valde istället att studera korrelationer mellan olika variabler och poängterar att de inte kan säga något om orsakerna bakom dessa samband. Huruvida många besök på ett science center förklarar ett stort intresse för naturvetenskap, eller tvärtom, uttalar sig författarna sig därför inte om. Studien, som baseras på kvantitativ data från 17 science centers i 13 länder, visade:

- Det fanns en signifikant korrelation mellan att besöka science centers och följande variabler: kunskap i och förståelse för naturvetenskap och teknik, intresse och nyfikenhet för naturvetenskap och teknik, engagemang med och intresse för naturvetenskap som skolämne, engagemang med naturvetenskapliga och teknikrelaterade aktiviteter utanför skolan, och identifikation och självsäkerhet med naturvetenskap och teknik.

- Korrelationerna ovan var starkare ju oftare besöken skedde, ju längre tid de tog och ju närmare i tiden de låg.

- Det tycks finnas gränser för kopplingarna till intresse och nyfikenhet. Upp till 2-4 besök per år är starkt associerat med ett ökat intresse. Fler besök har inte en lika tydlig koppling. När det gäller besökstiden fanns en tröskeleffekt, där korrelationen mellan tid spenderad på science centret och intresse var tämligen likartad för besök som varade upp till fyra timmar, men ökade för besök som var 5 timmar eller längre.

- Ovanstående var synligt oavsett karaktären på själva besöket (d.v.s. innehåll, upplägg etc.)

\section{Sammanfattning och några reflexioner}

Det är således väl belagt att informella lärmiljöer har potential att påverka elevers lärande och intresse i naturvetenskap. Som nämnts vid ett flertal tillfällen är det dock svårt hävda att en viss insats eller ett besök leder till ett specifikt utfall, som till exempel att en viss typ av kunnande härrör från ett besök på ett science centra man gjorde för ett par år sedan. På motsvarande sätt är det tveksamt att förklara en vuxen människas intresse, som det är synligt i karriärval, hobbys, vanor, etc., utifrån specifika händelser tidigare i livet. Forskning har också visat att saker som elever vanligtvis beskriver som intressant och kul, som till exempel experiment, inte nödvändigtvis leder till att de lär sig saker eller utvecklar ett intresse för naturvetenskap $[58,59]$.

Flera författare argumenterar istället för att man ska fokusera på vad olika informella lärmiljöer kan erbjuda för möjligheter till lärande och också tydliggöra på vilket sätt dessa kan fungera som komplement till skolans undervisning [7,9,60,61]. I relation till detta kan därför nedanstående aspekter lyftas ur den forskning som presenterats.

- Det sociala sammanhanget är viktigt. Flera studier lyfter det positiva i att eleverna får möjlighet att lämna skolan för att tillsammans med varandra, läraren och ämnesexperter interagera kring naturvetenskap i en stimulerande miljö.

- Informella lärmiljöer har potential att erbjuda alternativa ingångar till naturvetenskap.

- För att besöket ska påverka elevers intresse och lärande på ett mer beständigt sätt bör aktiviteten vara del i ett sammanhang. Av avgörande betydelse för detta är läraren. 
Att lära sig och eventuellt bli intresserad av naturvetenskap handlar alltså inte enbart om kunskap och attityder till ett ämnesstoff, utan även om att utveckla en förståelse för de sociala sammanhang där naturvetenskap är i fokus [62]. Positiva möten med ämnesföreträdare är därför viktiga då sådana tillfällen i någon mån innebär att eleverna får möjlighet att lära sig vad naturvetenskap utanför skolan kan betyda för dem personligen [63,64]. Lärande är en process som påverkas av oplanerade tillfälligheter, och material, klasskamrater och lärare har betydelse för vilka meningar som konstrueras av eleven [65]. Man kan således inte utgå från att en specifik aktivitet alltid har samma effekt på elevers lärande och intresse, utan de personer som är del i interaktionen är givetvis avgörande för vad som sker [64].

Ett återkommande tema i litteraturen är vikten av att besök och aktiviteter kopplas samman [33]. I princip innebär det att aktiviteten är begriplig och meningsfull för eleverna, dels i att de förstår vad de är satta att göra (syftet med aktiviteten) och dels i relation till vad de har gjort tidigare och till det de ska göra framöver. Vanligtvis beskrivs detta i termer av förberedelse- och efterarbete på skolan, vilket enligt litteraturen inte tycks förekomma i någon större utsträckning. Samtidigt som kontinuitet alltså framhålls som en mycket viktig faktor för elevernas lärande, har, bortsett från att klargöra aktiviteters mål och syften, informella lärmiljöer vanligtvis liten möjlighet att påverka detta. Salmi [48] visade i sin studie hur elevernas motivation att lära sig naturvetenskap förändrades över tid som ett resultat av ett mer formaliserat samarbete mellan skolan och det aktuella science centrat (Heureka i Helsingfors). Det framkommer dock inte i artikeln, annat än att eleverna var där en gång i månaden under ett år, vad samarbetet bestod i. Lyckade samarbeten, vad som kännetecknar dem och vad samarbetet innebär i relation till undervisning är därför ett område som bör undersökas närmare.

Avslutningsvis, artikeln har gett en översiktlig bild av informella miljöers påverkan på elevers intresse och lärande i naturvetenskap. I undantagsfall har mer undervisningsnära processer diskuterats i texten, vilket kanske beror på att flertalet studier framförallt rapporterar resultat från enkäter och intervjuer. Även om det finns exempel på mer undervisningsnära studier, se t.ex. [66] vore det intressant att undersöka detta lite närmare, det vill säga hur lärande och intresse utvecklas i mötet med museiguider, aktiviteter och föremål.

\section{Författare}

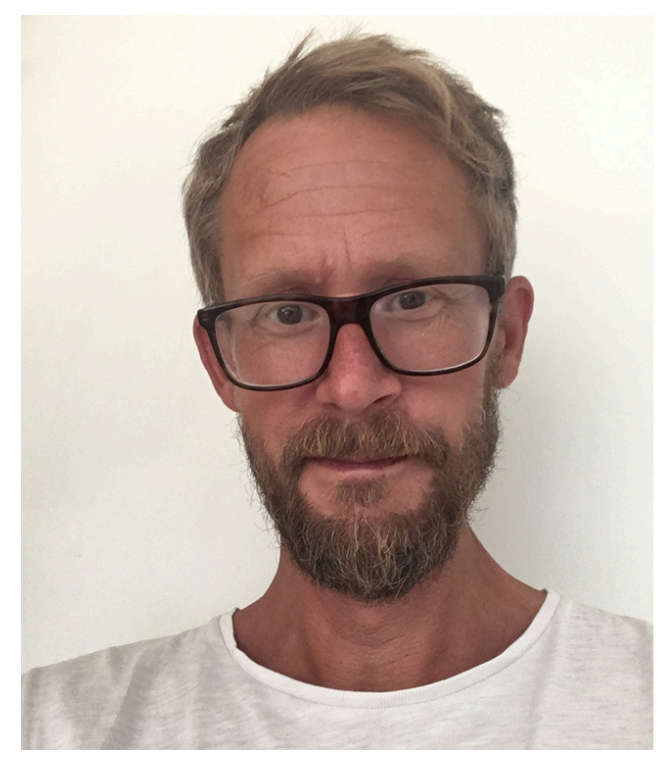

Figur 1. Per Anderhag arbetar som lektor på Stockholm stads utbildningsförvaltning samt är affilierad forskare på institutionen för matematikämnets och naturvetenskapsämnenas didaktik, Stockholms universitet. 


\section{Referenser}

1. Falk JH, Dierking LD. The museum experience revisited. Walnut Creek, CA: Left Coast Press; 2013.

2. Fortus D. Attending to affect. Journal of Research in Science Teaching. 2014;51(7).

3. Osborne J, Simon S, Collins S. Attitudes towards science: A review of the literature and its implications. International Journal of Science Education. 2003;25(9).

4. Ogawa RT, Loomis M, Crain R. Institutional history of an interactive science center: The founding and development of the Exploratorium. Science Education. 2009;93(2).

5. Rennie LJ, McClafferty TP. Science centres and science learning. Studies in Science Education. 1996;27(1).

6. Piqueras J. Extramuralt lärande i lärarutbildningen. Didaktikens Forum. 2007;4(1):56-74.

7. Bell P, Lewenstein B, Shouse A, Feder M. Learning science in informal environments: People, places, and pursuits. 2009;

8. Tytler R, Osborne J, Williams G, Tytler K, Cripps Clark J. Opening up pathways: Engagement in STEM across the Primary-Secondary school transition. 2008;.

9. Falk JH, Needham MD, Dierking LD, Prendergast L. International science centre impact study: Final report. 2014;

10. Potvin P, Hasni A. Interest, motivation and attitude towards science and technology at K-12 levels: A systematic review of 12?years of educational research. Studies in Science Education. 2014;50(1).

11. DeWitt J, Hohenstein J. Supporting student learning: A comparison of student discussion in museums and classrooms. Visitor Studies. 2010;13(1).

12. Phipps M. Research trends and findings from a decade (1997-2007) of research on informal science education and free-choice science learning. Visitor Studies. 2010;13(1).

13. Pedretti E. T. Kuhn meets T. Rex: Critical conversations and new directions in science centres and science museums. Studies in Science Education. 2002;37(1).

14. Kisiel J. Understanding elementary teacher motivations for science fieldtrips. Science Education. 2005;89(6).

15. Lucas KB. One teacher's agenda for a class visit to an interactive science center. Science Education. 2000;84(4).

16. Tal T, Morag O. School visits to natural history museums: Teaching or enriching?. Journal of Research in Science Teaching. 2007;44(5).

17. Rennie LJ. Learning science outside of school. I: Abell SK, Lederman NG, redaktörer. Handbook of research in science education. Mahwah, N: Lawrence Erlbaum Associate; 2007.

18. DeWitt J, Hohenstein J. Supporting student learning: A comparison of student discussion in museums and classrooms. Visitor Studies. 2010;13(1).

19. Cox-Petersen AM, Marsh DD, Kisiel J, Melber LM. Investigation of guided school tours, student learning, and science reform recommendations at a museum of natural history. Journal of Research in Science Teaching. 2003;40(2).

20. Guisasola J, Morentin M, Zuza K. School visits to science museums and learning sciences: A complex relationship. Physics Education. 2005;40(6).

21. Faria C, Chagas I. Investigating school-guided visits to an aquarium: What roles for science teachers?. International Journal of Science Education, Part B. 2013;3(2).

22. Bozdo?an AE, Yalç?n N. Determining the influence of a science exhibition center training program on elementary pupils' interest and achievement in science. EURASIA Journal of Mathematics, Science and Technology Education. 2009;5(1).

23. Griffin J, Symington D. Moving from task-oriented to learning-oriented strategies on school excursions to museums. Science Education. 1997;81(6).

24. Patrick P, Mathews C, Tunnicliffe SD. Using a field trip inventory to determine if listening to elementary school students' conversations, while on a zoo field trip, enhances preservice teachers' abilities to plan zoo field trips. International Journal of Science Education. 2013;35(15).

25. Griffin J. Research on students and museums: Looking more closely at the students in school 
groups. Science Education. 2004;88(S1).

26. Kisiel J. An examination of fieldtrip strategies and their implementation within a natural history museum. Science Education. 2006;90(3).

27. Tal T, Steiner L. Patterns of teacher?museum staff relationships: School visits to the educational centre of a science museum. Canadian Journal of Science, Mathematics and Technology Education. 2006;6(1).

28. Bamberger Y, Tal T. Multiple outcomes of class visits to natural history museums: The students' view. Journal of Science Education and Technology. 2008;17(3).

29. Bowker R. Children's perceptions of plants following their visit to the Eden Project. Research in Science \&amp; Technological Education. 2004;22(2).

30. Jarvis T, Pell A. Factors influencing elementary school children's attitudes toward science before, during, and after a visit to the UK National Space Centre. Journal of Research in Science Teaching. 2005;42(1).

31. Leinhardt G, Crowley K, Knutson K. Learning conversations in museums. Leinhardt G, Crowley K, Knutson K, redaktörer. Mahwah, NJ: Lawrence Erlbaum Associates; 2002.

32. Sample McMeeking LB, Weinberg AE, Boyd KJ, Balgopal MM. Student perceptions of interest, learning, and engagement from an informal traveling science museum. School Science and Mathematics. 2016;116(5).

33. Anderson D, Lucas KB, Ginns IS, Dierking LD. Development of knowledge about electricity and magnetism during a visit to a science museum and related post-visit activities. Science Education. 2000;84(5).

34. DeWitt J, Osborne J. Recollections of exhibits: Stimulated?recall interviews with primary school children about science centre visits. International Journal of Science Education. 2009;32(10).

35. Farmer AJ, Wott JA. Field trips and follow-up activities: Fourth graders in a public garden. The Journal of Environmental Education. 1995;27(1).

36. The impact of science and discovery centres: A review of worldwide studies. 2008;

37. Allen S. Looking for learning in visitor talk: A methodological exploration. I: Leinhardt K, Crowley K, Knutson K, redaktörer. Learning conversations in museums. Mahwah, NJ: Lawrence Erlbaum Associates; 2002.

38. Ash D. How families use questions at dioramas: Ideas for exhibit design. Curator: The Museum Journal. 2004;47(1).

39. Ayar MC. Examining the effect of Our World Exhibit on student visitors: A science center case. Science Education International. 2016;27(3):419-36.

40. Godec S. Home, school and the museum: Shifting gender performances and engagement with science. British Journal of Sociology of Education. 2020;41(2).

41. Dohn NB. Upper secondary students' situational interest: A case study of the role of a zoo visit in a biology class. International Journal of Science Education. 2013;35(16).

42. Orion N, Hofstein A. Factors that influence learning during a scientific field trip in a natural environment. Journal of Research in Science Teaching. 1994;31(10).

43. Anderson D, Nashon S. Predators of knowledge construction: Interpreting students' metacognition in an amusement park physics program. Science Education. 2007;91(2).

44. Stavrova O, Urhahne D. Modification of a school programme in the Deutsches Museum to enhance students' attitudes and understanding. International Journal of Science Education. 2010;32(17).

45. Basten M, Meyer-Ahrens I, Fries S, Wilde M. The effects of autonomy-supportive vs. controlling guidance on learners' motivational and cognitive achievement in a structured field trip. Science Education. 2014;98(6).

46. Dou R, Hazari Z, Dabney K, Sonnert G, Sadler P. Early informal STEM experiences and STEM identity: The importance of talking science. Science Education. 2019;103(3).

47. Goff EE, Mulvey KL, Irvin MJ, Hartstone-Rose A. The effects of prior informal science and math experiences on undergraduate STEM identity. Research in Science \&amp; Technological Education. 2019;38(3).

48. Salmi H. Science centres as learning laboratories: Experiences of Heureka, the Finnish science centre. International Journal of Technology Management. 2003;25(5). 
49. Coventry V. Major influences on career choice: A study conducted on behalf of Scitech Discovery Centre, Perth, Western Australia. Perth: Scitech Discovery Centre; 1997.

50. Shaby N, Vedder?Weiss D. Science identity trajectories throughout school visits to a science museum. Journal of Research in Science Teaching. 2020;57(5).

51. Stevenson J. The long?term impact of interactive exhibits. International Journal of Science Education. 1991;13(5).

52. Spock M. "When I grow up I'd like to work in a place like this": Museum professionals' narratives of early interest in museums. Curator: The Museum Journal. 2000;43(1).

53. Beiers R, McRobbie C. Learning in interactive science centres. Research in Science Education. 1992;22(1).

54. Anderson D. Visitors' long-term memories of world expositions. Curator: The Museum Journal. 2003;46(4).

55. Falk JH, Reinhard EM, Vernon CL, Bronnenkant K, Heimlich JE, Deans NL. Why zoos and aquariums matter: Assesing the impact of a visit to a zoo or aquarium. Silver Spring, MD: Association of Zoos \&amp; Aquariums; 2007.

56. Falk JH, Needham MD. Measuring the impact of a science center on its community. Journal of Research in Science Teaching. 2011;48(1).

57. Jensen $\mathrm{E}$, Lister $\mathrm{T}$. The challenges of 'measuring long-term impacts of a science center on its community': A methodological review. I: Patrick P, redaktör. Preparing Informal Science Educators. Cham: Springer; 2017.

58. Abrahams I. Does practical work really motivate? A study of the affective value of practical work in secondary school science. International Journal of Science Education. 2009;31(17).

59. Abrahams I, Millar R. Does practical work really work? A study of the effectiveness of practical work as a teaching and learning method in school science. International Journal of Science Education. 2008;30(14).

60. Mujtaba T, Lawrence M, Oliver M, Reiss MJ. Learning and engagement through natural history museums. Studies in Science Education. 2018;54(1).

61. Peacock A, Pratt N. How young people respond to learning spaces outside school: A sociocultural perspective. Learning Environments Research. 2011;14(1).

62. Lemke JL. Talking science: Language, learning and values. Norwood, NJ: Ablex; 1990.

63. Johansson KE. House of science: A university laboratory for schools. Physics Education. 2004;39(4).

64. Piqueras J, Seneby N, Hamza KM. Learning from young experts. A study of the interplay between students and young experts in a biology lab. 2008;.

65. Hamza KM, Wickman P-O. Beyond explanations: What else do students need to understand science?. Science Education. 2009;93(6).

66. Piqueras J, Hamza KM, Edvall S. The practical epistemologies in the museum. Journal of Museum Education. 2008;33(2). 